\title{
A cooperative computerized concept-mapping approach to improving students' learning performance in web-based information-seeking activities
}

\author{
Hui-Chun Chu • Gwo-Jen Hwang • Yi-Rong Liang
}

Received: 17 September 2013/Revised: 17 December 2013/Accepted: 5 February 2014/

Published online: 19 March 2014

(C) Beijing Normal University and Springer-Verlag Berlin Heidelberg 2014

\begin{abstract}
Concept mapping has been widely adopted in the past few decades as an instructional or learning tool for helping students organize their knowledge; nevertheless, several previous studies have indicated the difficulty of applying this approach. In particular, for elementary school students, developing concept maps could be a difficult task, implying the importance of providing supports during the learning process. In this study, a computerized, cooperative concept-mapping approach is proposed to assist students in interpreting and organizing data collected in web-based information-seeking activities. To evaluate the effectiveness of this approach, a learning activity has been conducted on an elementary school natural science course. Two-hundred-and-twenty-fifth graders from seven classes were divided into an experimental group, in which the students learned with the proposed approach; and a control group, in which the students learned with the conventional computerized concept-mapping approach. From the experimental results, it was found that the students in the experimental group had significantly better learning attitudes, self-efficacy, and achievements than those in the control group. In the meantime, the cognitive load of the experimental group students was significantly
\end{abstract}

\footnotetext{
H.-C. Chu

Department of Computer Science and Information Management, Soochow University, Taipei, Taiwan

e-mail: carolhcchu@gmail.com

G.-J. Hwang ( $\square)$

Graduate Institute of Digital Learning and Education, National Taiwan University of Science and Technology, Taipei, Taiwan

e-mail: gjhwang.academic@gmail.com

Y.-R. Liang

Chiayi County Tong-Rong elementary school, Chiayi, Taiwan

e-mail: alex@mail.trps.cyc.edu.tw
} 
lower than that of the control group students, implying the effectiveness of the proposed approach.

Keywords Concept map · Cooperative learning - Self-efficacy ·

Cognitive load · Web-based information-seeking

\section{Background and objectives}

Engaging students in searching for information on the web to answer a series of questions related to a target issue has been identified to be an important educational objective nowadays (Bilal 2002; Tseng et al. 2009). Such learning activities have been called web-based problem solving (Hwang and Kuo 2011). Researchers have indicated that, when trying to search for information on the web to answer the questions, students not only need to know how to use search engine and keywords, but also require the ability of selecting web pages related to the target issue, abstracting web contents from the selected pages, organizing the derived information, and making summarization (Chiou et al. 2009; Tsai et al. 2012); moreover, it has been reported that most students have difficulties in organizing and summarizing information instead of searching for it (Hwang and Kuo 2011). Consequently, it is important to lead in knowledge construction tools to help students organize the searched information in web-based problem-solving activities.

In the past few decades, concept maps have been widely used, no matter whether in traditional in-class instruction or in computer-assisted learning. Many studies have reported the effectiveness of using concept maps as a knowledge organizing tool (Chiou 2008; Chu et al. 2010a; Hwang et al. 2011a, b); for example, Hwang et al. (2011b) employed a computerized concept-mapping approach in an elementary school natural science course and found it to be beneficial to the students in improving their learning performance. On the other hand, several studies have revealed the problems of applying this approach (Charsky and Ressler 2011); for example, Lim et al. (2009) indicated that students might fail to successfully develop concept maps owing to their lack of self-regulated learning skills. They also reported that learner-generated concept maps were more helpful to students than the expert-generated ones. Consequently, it is important to provide learning supports to help students develop their own concept maps in an effective way, in particular, for those elementary school students who might have difficulty in developing concept maps to interpret and organize what they have learned or the data collected on the Internet. It is also valuable to investigate the students' perceptions of developing concept maps with different learning strategies, such as learning attitudes and selfefficacy, as well as their learning performance (Tzeng 2009).

Researchers have indicated that cooperative learning can be considered as a potential learning strategy that can help students cope with difficult learning tasks via peer interaction (Hwang et al. 2008; Kao et al. 2008, 2012). In a cooperative learning activity, students are assigned to groups and are encouraged to work cooperatively to complete their learning tasks. Johnson and Johnson (1994) indicated that successful cooperative learning requires a definite goal which 
everyone can work together to complete, and emphasized the responsibility of each team member, such that the cultivation of social skills is emphasized in the cooperative process. In addition, cooperative learning is able to help students cultivate responsible attitudes in the learning process (Gillies 2004).

Consequently, this study aimed to propose a computerized concept-mapping approach to improving the learning performance of students in web-based problemsolving activities, in which students need to search for data on the web, select the searched web pages, abstract information from the selected pages, and summarize their findings to answer a series of questions related to the target issue. Moreover, to investigate the effectiveness of the proposed approach, an experiment was conducted on an elementary school natural science course to answer the following research questions:

(1) Is there a significant difference between the learning achievements of the students who learn with the cooperative computerized concept-mapping strategy and the conventional computerized concept-mapping strategy in webbased information-seeking activities?

(2) Is there a significant difference between the learning attitudes of the students who learn with the cooperative computerized concept-mapping strategy and the conventional computerized concept-mapping strategy in web-based information-seeking activities?

(3) Is there a significant difference between the self-efficacy beliefs of the students who learn with the cooperative computerized concept-mapping strategy and the conventional computerized concept-mapping strategy in web-based information-seeking activities?

(4) Is there a significant difference between the cognitive loads of the students who learn with the cooperative computerized concept-mapping strategy and the conventional computerized concept-mapping strategy in web-based information-seeking activities?

(5) Are there notable correlations between students' cognitive load and their learning achievement with different computerized concept-mapping strategies?

\section{Literature review}

\section{Concept mapping}

Concept mapping was proposed by Novak and Gowin (1984) based on the specific learning strategy of meaningful learning proposed by Ausubel (1968). It is an effective teaching strategy as it can clearly present the concept structures of the learners as well as identify the misconceptions of the learners (Novak et al. 1983). In the last decade, the popularity of computer technologies has further provided a more efficient way of using computerized maps in education (Erdogan 2009). Researchers have indicated that with the assistance of computer technologies, the development of concept maps has become easier than when using the paper-and-pencil approach (Erdogan 2009). Several studies have reported the benefits of using computerized 
concept mapping in educational settings. For example, Kao et al. (2008) showed that concept mapping was able to increase the creative performance of students as well as their conceptual self-awareness; Liu et al. (2010) reported that the computerassisted concept-mapping learning strategy was able to improve the English reading comprehension of English as a Foreign Language (EFL) college students; and Wu et al. (2012) demonstrated the effectiveness of using computerized concept-mapping tools in a nursing course.

In the meantime, researchers have also indicated the importance of using the concept-mapping approach in proper ways. For example, the study of Charsky and Ressler (2011) showed that this approach could cause negative effects if students were unable to understand the role and usage of concept maps during their learning process. Tzeng (2009) further emphasized that, in learning activities which involve developing concept maps, most students tend to overestimate their ability of completing their learning tasks; that is, they might encounter various unexpected problems during the concept-map-constructing process, implying the importance and necessity of providing them with additional learning supports, in particular, for those elementary school students who are not proficient in using computers or in constructing knowledge.

\section{Cooperative learning}

Vygotsky (1986) has indicated that culture and social roles are important in the learning process and can be regarded as the major power for intelligence development via social interactions. Brown and Duguid (1989) considered that, knowledge being implied in contexts, individuals would construct their own knowledge in the process of constant interactions with the context and in the process of acquiring knowledge, which could not be separated from the context as knowledge is constructed from interactions between humans and the environment. Accordingly, educators have pointed out that knowledge construction requires continuous communication with and modification by others; that is, knowledge construction is considered as the consensus arrived at after the interactions and communications between individuals and the social environment (von Glasersfeld 1995).

Slavin (1995) further regarded cooperative learning as a structural and systematic teaching strategy, and suggested that teachers allocate students with different abilities, genders, races, and backgrounds to heterogeneous groups of 4-6 persons to learn together. The students would assist each other in comprehending the learning contents, and the team members would try to understand each other by way of constant discussion, and thus master the learning contents in the process.

In the last decade, cooperative learning has been applied to various technologyenhanced learning activities. For example, Kuo et al. (2012a) employed a cooperative approach to assist students in learning in a web-based problem-solving activity in which the students needed to answer a series of questions related to the target issue by searching for information on the web. They found that the middleand low-achievement students gained significant benefits from the approach. In the meantime, AbuSeileek (2012) investigated the effect of computer-based cooperative 
learning on EFL students' achievement in speaking and writing. They found that the computer-based environment could reduce the students' anxiety in comparison with face-to-face interactions, which was helpful to them in developing their communication skills.

On the other hand, Prinsen et al. (2009, p. 1) stated that “... to involve students in productive dialogue, simply providing a medium is not sufficient." They further indicated that "Learner involvement is facilitated by the instructional design principles that are embedded in the larger CSCL environment." That is, it is important to provide learning supports during the cooperative learning process, and the provision of concept-mapping strategies and tools could be an effective support to students. Therefore, in this study, the effectiveness of a cooperative conceptmapping approach is investigated in terms of learning performance, attitudes, and self-efficacy.

\section{Research design}

To evaluate the performance of the proposed approach, a web-based problemsolving activity was conducted in an elementary school natural science course. Such activities have been recognized by researchers as being a potential way of improving the problem-solving ability and knowledge structure of students (Eisenberg and Berkowitz 1990; Kuo et al. 2012a, b) and have been widely adopted in elementary schools in Taiwan.

\section{Participants}

The participants were two-hundred-and-twenty-fifth graders from seven classes of an elementary school in southern Taiwan. The average age of the students was 11. Four classes $(N=125)$ were assigned to the experimental group, and three classes constituted the control group $(N=95)$. The students in the experimental group learned with the cooperative computerized concept-mapping strategy, while those in the control group learned with the conventional computerized concept-mapping approach. Both groups of students were instructed by the same teacher.

The learning environment and knowledge construction tool

Figure 1 shows the interface of the web-based learning environment adopted in this study. It consists of a problem-solving interface, a search engine, and a concept map tool. The problem-solving interface enables teachers to prepare a series of questions related to a specific issue. When students log in the learning system and select the issue, the questions are displayed in the predefined order. Students can use the search engine to search for information on the Internet, select the searched pages, abstract the web content using the copy and paste function, organize the content, make summarization, and submit the answer. In addition, a concept-mapping tool, CmapTools, developed by the Institute for Human \& Machine Cognition (IHMC), is provided to help students organize what they have found on the web by presenting 


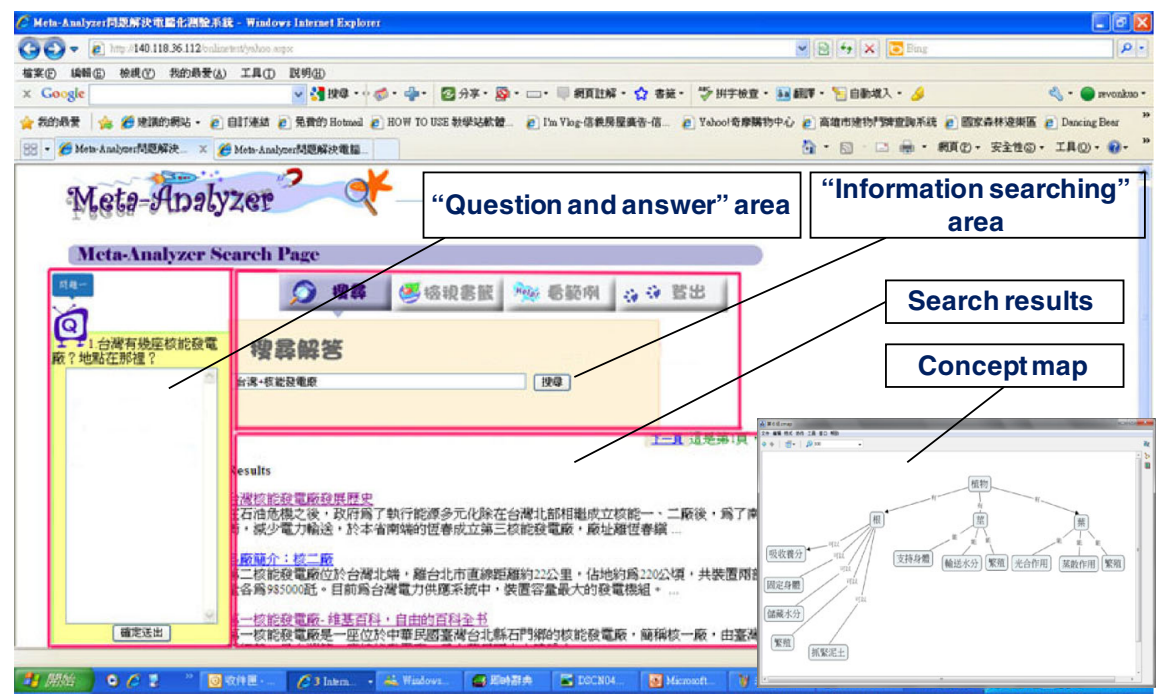

Fig. 1 Interface of the learning environment

the collected information in the map. With the help of concept maps, students are able to clarify the relationships between the concepts or data items abstracted from the web contents, and hence make summarizations for answering the questions in an effective way.

\section{Experimental procedure}

Before the experiment, the students took a pre-test to evaluate their basic knowledge concerning the subject unit "The Roots, Stems, and Leaves of Plants" of the natural science course. Based on the pre-test scores, the students in both the experimental and control groups were assigned to small heterogeneous learning groups with five students per group.

The learning activity consisted of six 40-min sessions over a period of 2 week, In the beginning of the web-based problem-solving activity, a 40-min orientation was given to introduce the learning tasks, the conception of concept mapping, and the computerized concept-mapping tool to the students in both groups.

Following the orientation, both groups of students were asked to collect data for answering a series of questions related to the target issue on the web in five sessions. The experimental group was guided to work cooperatively based on the Learning Together (LT) strategy (Johnson and Johnson 1991), as it emphasizes learning as the common responsibility of the group members. In this learning activity, the students were evaluated based on their cooperative learning results (the developed concept maps and their web-based learning performance); that is, they were encouraged to share their knowledge and work together.

In the meantime, the students were asked to develop concept maps based on the collected data. As indicated by researchers, during a web-based problem-solving activity, students need to search for information (using keywords with search 
engine), select searched web pages to browse, abstract information from the browsed pages, organize the information, and answer the questions. It can be seen that the use of concept-mapping approach could be helpful to the students in the information-abstracting and organizing phases.

After the learning activity, all students took a post-test and filled in the questionnaires of learning attitude and cognitive load.

\section{Measuring tools}

The pre-test and the post-test were developed by two experienced teachers who had taught the course for more than 5 years and were evaluated by a researcher who had nearly 10 years' experience in developing test items. Both the pre-test and post-test sheets consisted of 15 yes-or-no questions, 20 multiple-choice questions, and 2 essay questions. The perfect score of the tests was 100 .

The questionnaire of learning attitude toward Science was developed by Chu et al. (2010b). It consists of six items with a 4-point rating scale. The Cronbach's $\alpha$ value of the questionnaire was 0.78 , showing high reliability.

The self-efficacy scale was developed by Hwang et al. (2011). It consists of seven items with a 4-point rating scale. The Cronbach's $\alpha$ value of the questionnaire was 0.85 , showing high reliability.

The cognitive load measure employed in this study was proposed by Sweller et al. (1998). It consists of two items for the mental load and two items for the mental effort dimensions with a 7-point rating scale. The Cronbach's alpha values of the two dimensions were 0.84 and 0.82 , respectively.

\section{Results}

\section{Learning achievement}

Having discussed the introduction of cooperative concept mapping to the experimental group, the differences in learning achievement were further analyzed. Before the experiment, both the experimental and the control groups took a learning achievement pre-test to identify the entry capability of the students. The data further underwent an Independent Sample $t$ test, as shown in Table 1. No significant difference appeared in the test results of the two groups, indicating that the prior knowledge of the two groups was equivalent.

The post-test was administered after the learning activity. Table 2 shows the learning achievement of the two groups. A significant difference $(t=2.7, p<.01)$

Table $1 t$ test result of the pre-test scores of the two groups

\begin{tabular}{lclll}
\hline Group & Number & Mean & Standard deviation & $t$ \\
\hline The experimental group & 125 & 60.62 & 12.59 & 1.14 \\
The control group & 95 & 58.72 & 11.78 & \\
\hline
\end{tabular}


Table $2 t$ test result of post-test scores of the two groups

\begin{tabular}{lclll}
\hline Group & Number & Mean & Standard deviation & $t$ \\
\hline The experimental group & 125 & 75.18 & 14.98 & $2.70 * *$ \\
The control group & 95 & 69.92 & 13.34 & \\
\hline
\end{tabular}

$* * p<.01$

was found, showing that the cooperative computerized concept-mapping approach could effectively promote the learning achievement of the students in comparison with the individual computerized concept-mapping approach.

Learning attitude toward science

Table 3 shows the Independent Sample $t$ test result of analyzing the learning attitude toward Science of the two groups. A notable difference was found between the two groups $(t=4.08, p<.001)$, indicating that the cooperative computerized conceptmapping approach was able to improve the students' learning attitudes toward Science in comparison with the individual computerized concept-mapping approach.

\section{Self-efficacy of learning with computerized concept mapping}

Self-efficacy refers to a person's belief in his/her capabilities to execute the required actions to complete the assigned learning tasks in a course (Bandura 1997; Wang and Hwang 2012). It has been recognized by researchers as a very effective predictor of students' learning motivation and academic achievement (Zimmerman 2000); therefore, it is important to investigate whether the proposed approach improved the self-efficacy of the students.

Table 4 shows the Independent Sample $t$ test result of analyzing the self-efficacy of the two groups in learning with the computerized concept-mapping approach. A significant difference was found between the two groups $(t=4.17, p<.001)$, indicating that the cooperative computerized concept-mapping approach could effectively enhance students' self-efficacy in comparison with the individual computerized concept mapping. That is, the proposed approach enhanced the students' beliefs in their capabilities of achieving the learning goals. According to previous studies related to self-efficacy, such a belief enhancement is helpful to students in improving their learning achievement (Zimmerman 2000).

\section{Cognitive load}

The conception of cognitive load was proposed by Sweller (1988), and refers to the load resulting from a specific task needing to be processed by the learner's cognitive system. Jex (1988) considered cognitive load as the differences of mental load between the task requirement and the self-cognitive ability when learners tend to present proper task behaviors in a relative learning context. Paas (1992) indicated 
Table $3 t$ test result of the students' learning attitude toward science

\begin{tabular}{lclll}
\hline Group & Number & Mean & Standard deviation & $t$ \\
\hline Experimental group & 125 & 3.48 & 0.25 & $4.08^{* * * *}$ \\
Control group & 95 & 3.29 & 0.45 & \\
\hline
\end{tabular}

$* * * p<.001$

Table $4 t$ test result of the students' self-efficacy in learning with the concept-mapping approach

\begin{tabular}{lclll}
\hline Group & Number & Mean & Standard deviation & $t$ \\
\hline Experimental group & 125 & 3.35 & 0.47 & $4.17 * * *$ \\
Control group & 95 & 3.05 & 0.58 & \\
\hline
\end{tabular}

$* * * p<.001$

that cognitive load is a multidimensional concept consisting of both mental load and mental effort. The former is related to the difficulty levels and amount of learning materials as well as to the students' knowledge levels, while the latter is related to the learning strategy or how the learning materials are organized and presented.

Table 5 shows the $t$ test result of the mental load of the two groups. A significant difference $(t=-4.81, p<.001)$ was found, implying that the cooperative computerized concept-mapping approach produced notable effects on reducing the students' mental load. That is, with the cooperative computerized conceptmapping approach, the experimental group presented significantly lower mental effort than the control group. In other words, it could ease the load of the students in understanding the learning materials that were difficult to them via the interactions and cooperation among peers.

Table 6 shows the analysis result of the Independent Sample $t$ test of mental effort of the two groups. A significant difference $(t=-5.19, p<.001)$ was found, implying that the cooperative computerized concept-mapping approach had significant effects on the students' mental effort. In other words, the proposed approach could effectively help the students organize what they were learning via the cooperation of the team members.

Correlations between cognitive load and learning achievements

Several studies have reported that cognitive load can be reduced by properly designing and organizing learning tasks, and learning contents and strategies; that is, cognitive load can be used to explain the effects of learning designs on students' learning performance (Hwang and Chang 2011; Paas et al. 2003a, b).

To understand the correlations between the mental load and the post-test of the students with the cooperative computerized concept-mapping approach, Pearson correlation was utilized. The correlation analyses of the experimental group showed a negative correlation, as shown in Table 7 , presenting that the cooperative computerized concept-mapping approach could assist the students in reducing their 
Table $5 t$ test result of the mental load of the two groups

\begin{tabular}{lclll}
\hline Group & Number & Mean & Standard deviation & $t$ \\
\hline Experimental group & 125 & 2.27 & 1.06 & $-4.81^{* * * *}$ \\
Control group & 95 & 3.09 & 1.49 & \\
\hline
\end{tabular}

$* * * p<.001$

Table $6 t$ test result of the mental effort of the two groups

\begin{tabular}{lcclc}
\hline Group & Number & Mean & Standard deviation & $t$ \\
\hline Experimental group & 125 & 3.42 & 1.26 & $-5.19 * * *$ \\
Control group & 95 & 4.33 & 1.32 & \\
\hline
\end{tabular}

$* * * p<.001$

Table 7 Analyses of mental load in cognitive load and the post-test achievement of the experimental group $(N=125)$

\begin{tabular}{llll}
\hline & & Post-test scores & Mental load \\
\hline Post-test scores & $\begin{array}{l}\text { Pearson correlation } \\
\text { Significance (double tail) }\end{array}$ & 1 & $-0.20^{*}$ \\
Mental load & Pearson correlation & $-0.20^{*}$ & 0.02 \\
& Significance (double tail) & 0.02 & 1 \\
\hline
\end{tabular}

$* p<.05$

mental load in the learning process as well as enhance their learning achievement on the post-test. On the other hand, the correlation analyses of the control group were not significant, as shown in Table 8. Such findings provide further evidence to explain why the learning achievement of the experimental group was significantly better than that of the control group from the aspect that the peer cooperation was helpful to the students in efficiently and effectively understanding the difficult learning content.

Furthermore, to understand the correlations between the experimental group students' mental effort and their post-test scores, Pearson correlation analysis was conducted, as shown in Table 9. A significantly negative correlation was found, implying that the cooperative computerized concept-mapping approach could reduce the students' mental effort in the learning process as well as enhance their learning achievement. On the other hand, Table 10 shows the Pearson correlation analysis of the control group. It was found that the correlation was not significant, implying that the conventional computerized concept mapping was not helpful to the students in decreasing their mental effort. Such findings provide evidence from the aspect that the peer cooperation was helpful to the students in interpreting and organizing what they were learning by employing the concept-mapping strategy in an efficient and effective way. 
Table 8 Analyses of mental load in cognitive load and the post-test achievements of the control group $(N=95)$

\begin{tabular}{llll}
\hline & & Post-test scores & Mental load \\
\hline Post-test scores & Pearson correlation & 1 & 0.04 \\
& Significance (double tail) & & 0.67 \\
Mental load & Pearson correlation & 0.04 & 1 \\
& Significance (double tail) & 0.67 & \\
\hline
\end{tabular}

Table 9 Analyses of mental effort in cognitive load and the post-test achievement of the experimental group $(N=125)$

\begin{tabular}{llll}
\hline & & Post-test scores & Mental effort \\
\hline Post-test scores & Pearson correlation & 1 & $-0.30^{* *}$ \\
& Significance (double tail) & & 0.001 \\
Mental effort & Pearson correlation & $-0.30^{* *}$ & 1 \\
& Significance (double tail) & 0.001 & \\
\hline
\end{tabular}

$* * p<.01$

Table 10 Analyses of mental effort in cognitive load and the post-test achievements of the control group $(N=95)$

\begin{tabular}{llll}
\hline & & Post-test scores & Mental effort \\
\hline Post-test scores & Pearson correlation & 1 & -0.07 \\
& Significance (double tail) & & 0.52 \\
Mental effort & Pearson correlation & -0.07 & 1 \\
& Significance (double tail) & 0.52 & \\
\hline
\end{tabular}

\section{Discussion and conclusions}

In this study, a cooperative concept-mapping approach for conducting web information-searching activities was proposed; moreover, an experiment was conducted to investigate the effects of the proposed approach on students' learning achievement, learning attitudes, self-efficacy, and cognitive load. The experimental results showed that the students who learned with the cooperative computerized concept-mapping approach outperformed those who learned with the conventional computerized concept-mapping approach. The result corresponds to the hypothesis that students who take part in cooperative computerized concept-map-supported learning would be able to achieve better learning achievement than those who experience individual computerized concept-map-supported learning. In addition, the experimental results also showed that cooperative computerized conceptmapping learning could improve their learning attitudes toward Science and their self-efficacy of achieving the learning goals. 
As self-efficacy refers to the students' beliefs in completing the learning tasks, it is reasonable to owe the high self-efficacy of the experimental group students to the peer interactions and cooperation during the concept-mapping process. That is, with the assistance and support from their team members, most students in the experimental group felt more confident about carrying out the information-seeking tasks and developing the concept maps; on the contrary, those in the control group showed less confidence although they were taught to use the concept-mapping strategy to organize the collected data. As researchers have indicated that selfefficacy can be an effective predictor of students' learning motivation and academic achievement, the significantly higher self-efficacy of the experimental group provides evidence to explain why the students who learned with the cooperative computerized concept-mapping approach showed significantly better learning attitudes and academic achievements than the control group.

Furthermore, from the cognitive load measure, it was found that the mental load of the experimental group appeared significantly lower than that of the control group; moreover, the learning achievement of the experimental group students was negatively related to their mental load. This implies that the cooperative computerized concept-mapping approach could assist the students in understanding the learning content that might be difficult for them or beyond their prior knowledge, and hence improved their academic achievement. Such a finding is consistent with what has been reported by those previous studies related to cooperative or collaborative learning (Gillies 2004; Hwang and Chang 2011).

On the other hand, the results from examining the mental effort of the students even provided some additional interesting findings. The $t$ test result showed that the experimental group students had significantly lower mental effort than those in the control group; in the meantime, the Pearson correlation analysis revealed that the experimental group students' mental effort was negatively related to their learning achievement. As mental effort refers to the strategies used to provide learning supports to students in terms of interpreting and organizing their knowledge during the learning process, it was concluded that the cooperation and interactions among the team members did help the students efficiently and effectively employ the concept-mapping strategies to represent and organize what they had collected and discussed on the web.

The researchers of this study further interviewed the students to examine those issues in depth. It was found that most of the low-achievement students presented good communications and interactions with their classmates in the same group. They indicated that, with the cooperative computerized concept-mapping approach, they could seek help from the high-achievement students when they could not understand some learning content or collected data. They also believed that they would learn better via the cooperative computerized concept-mapping process. In the meantime, most of the high-achievement students revealed that they were glad to teach and help their team members. Consequently, the interactions and discussions in the cooperative learning groups were frequent and successful. This corresponds to the finding of Gillies's study (2004) that peers are likely to help each other and cultivate responsible attitudes in a cooperative learning context if the cooperative learning tasks are well designed. 
Another notable issue is that the learning activity conducted in this study was related to web-based information-seeking tasks, in which students needed to search for data on the web, select searched web pages, abstract information from the selected pages, and summarize the information to answer a series of questions related to the target issue. Bilal (2002) indicated that the lack of effective information searching strategies and high-order thinking abilities would influence students' web-based information-seeking and summarizing performance. Kuo et al. $(2012 \mathrm{a}, \mathrm{b})$ further indicated that it would be difficult for students to enhance their high-order thinking ability without proper supports in the web-based informationseeking tasks. Although concept mapping has been recognized as being an effective approach for helping students organize their knowledge by linking their new concepts to the old ones in a structured and visualized way, the learning performance and cognitive load of the students in the control group showed that most of them failed to comprehend and organize those collected data with the concept-mapping approach on their own. Their self-efficacy and learning attitudes further indicated that they were not confident in developing the concept maps based on the collected data. In that case, concept mapping might not be helpful to them. Such a finding conforms to the fact indicated by several previous studies that the effectiveness of concept-map-based approach is not obvious (Hwang et al. 2014, 2013); that is, careful learning design is needed for applying concept mapping to educational settings.

From the above discussions, it is concluded that additional supports are needed for helping students employ the computerized concept-mapping approach to interpret and organize what they have learned, in particular, the large amount of data they have collected from the web. Moreover, cooperative computerized concept mapping could be a good strategy to enhance the self-efficacy and decrease the cognitive load of students, such that their learning attitude toward science as well as their learning achievement can be improved.

Acknowledgments This study is supported in part by the National Science Council of the Republic of China under contract numbers NSC 101-2511-S-011-005-MY3, NSC 102-2511-S-011-007-MY3, and NSC 101-2628-S-031-001-MY2.

\section{References}

AbuSeileek, A. F. (2012). The effect of computer-assisted cooperative learning methods and group size on the EFL learners' achievement in communication skills. Computers and Education, 58(1), 231-239.

Ausubel, D. P. (1968). Educational psychology: A cognitive view. New York: Holt, Rinehart and Winston.

Bandura, A. (1997). Self-efficacy: The exercise of control. NY: Freeman.

Bilal, D. (2002). Children's use of the Yahooligans! Web search engine. III. Cognitive and physical behaviors on fully self-generated search tasks. Journal of the American Society for Information Science and Technology, 53(13), 1170-1183.

Brown, C., \& Duguid, (1989). Situated cognition and the culture of learning. Educational Researcher, 18, $32-42$.

Charsky, D., \& Ressler, W. (2011). Games are made for fun: Lessons on the effects of concept maps in the classroom use of computer games. Computers and Education, 56, 604-615. 
Chiou, C. C. (2008). The effect of concept mapping on students' learning achievements and interests. Innovations in Education and Teaching International, 45(4), 375-387.

Chiou, C. K., Hwang, G. J., \& Tseng, J. C. R. (2009). An auto-scoring mechanism for evaluating problem-solving ability in a web-based learning environment. Computers and Education, 53(2), 261-272.

Chu, H. C., Hwang, G. J., \& Huang, Y. M. (2010a). An enhanced learning diagnosis model based on concept-effect relationships with multiple knowledge levels. Innovations in Education and Teaching International, 47(1), 53-67.

Chu, H. C., Hwang, G. J., \& Tsai, C. C. (2010b). A knowledge engineering approach to developing Mindtools for context-aware ubiquitous learning. Computers and Education, 54(1), 289-297.

Eisenberg, M. B., \& Berkowitz, R. E. (1990). Information problem-solving: The big six skills approach to library and information skills. Norwood, NJ: Ablex publishing Corp.

Erdogan, Y. (2009). Paper-based and computer-based concept mappings: The effects on computer achievement, computer anxiety and computer attitude. British Journal of Educational Technology, 40(5), 821-836.

Gillies, R. M. (2004). The effects of cooperative learning on junior high school students during small group learning. Learning and Instruction, 14(2), 197-213.

Hwang, G. J., \& Chang, H. F. (2011). A formative assessment-based mobile learning approach to improving the learning attitudes and achievements of students. Computers and Education, 56(1), 1023-1031.

Hwang, G. J., \& Kuo, F. R. (2011). An information-summarising instruction strategy for improving the web-based problem solving abilities of students. Australasian Journal of Educational Technology, 27(2), 290-306.

Hwang, G. J., Kuo, F. R., Chen, N. S., \& Ho, H. J. (2014). Effects of an integrated concept mapping and web-based problem-solving approach on students' learning achievements, perceptions and cognitive loads. Computers and Education, 71, 77-86.

Hwang, G. J., Shi, Y. R., \& Chu, H. C. (2011a). A concept map approach to developing collaborative Mindtools for context-aware ubiquitous learning. British Journal of Educational Technology, 42(5), $778-789$.

Hwang, G. J., Wu, P. H., \& Ke, H. R. (2011b). An interactive concept map approach to supporting mobile learning activities for natural science courses. Computers and Education, 57(4), 2272-2280.

Hwang, G. J., Yang, L. H., \& Wang, S. Y. (2013). A concept map-embedded educational computer game for improving students' learning performance in natural science courses. Computers and Education, 69(1), 121-130.

Hwang, G. J., Yin, P. Y., Hwang, C. W., \& Tsai, C. C. (2008). An enhanced genetic approach to composing cooperative learning groups for multiple grouping criteria. Educational Technology and Society, 11(1), 148-167.

Jex, H. R. (1988). Measuring mental working: Problems, progress, and promises. In P. A. Hancock, \& N. M. Meshkati (Eds.), Human mental workload (pp. 5-40). Amsterdam: Elsevier.

Johnson, D. W., \& Johnson, R. T. (1991). Learning together and alone. Boston: Allyn and Bacon.

Johnson, D. W., \& Johnson, R. T. (1994). Learning together and alone: cooperative, competitive, and individualistic learning (4th ed.). Boston: Allyn and Bacon.

Kao, G. Y. M., Lin, S. S. J., \& Sun, C. T. (2008). Beyond sharing: Engaging students in cooperative and competitive active learning. Educational Technology and Society, 11(3), 82-96.

Kuo, F. R., Hwang, G. J., Chen, S. C., \& Chen, Sherry Y. (2012a). A cognitive apprenticeship approach to facilitating web-based collaborative problem solving. Educational Technology and Society, 15(4), 319-331.

Kuo, F. R., Hwang, G. J., \& Lee, C. C. (2012b). A hybrid approach to promoting students' web-based problem-solving competence and learning attitude. Computers and Education, 58(1), 351-364.

Lim, K. Y., Lee, H. W., \& Grabowski, B. (2009). Does concept mapping strategy work for everyone? The levels of generativity and learners' self-regulated learning skills. British Journal of Educational Technology, 40(4), 606-618.

Liu, P. L., Chen, C. J., \& Chang, Y. J. (2010). Effects of a computer-assisted concept mapping learning strategy on EFL college students' English reading comprehension. Computers and Education, 54(2), 436-445.

Novak, J., \& Gowin, D. (1984). Learning how to learn. Cambridge: Cambridge University Press.

Novak, J. D., Gowin, D. B., \& Johansen, G. T. (1983). The use of concept mapping and knowledge vee mapping with junior high school science students. Science Education, 67(5), 625-645. 
Paas, F. G. W. C. (1992). Training strategies for attaining transfer of problem-solving skill in statistics: A cognitive load approach. Journal of Educational Psychology, 84, 429-434.

Paas, F., Renkl, A., \& Sweller, J. (2003a). Cognitive load theory and instructional design: Recent developments. Educational Psychologist, 38(1), 1-4.

Paas, F., Tuovinen, J. E., Tabbers, H. K., \& Van Gerven, P. W. M. (2003b). Cognitive load measurement as a means to advance cognitive load theory. Educational Psychologist, 38(1), 63-71.

Prinsen, F. R., Volman, M. L. L., Terwel, J., \& van den Eeden, P. (2009). Effects on participation of an experimental CSCL-programme to support elaboration: Do all students benefit? Computers and Education, 52, 13-125.

Slavin, R. E. (1995). Cooperative learning: theory, research, and practice (2nd ed.). Boston, MA: Allyn and Bacon.

Sweller, J. (1988). Cognitive load during problem solving: Effect on learning. Cognitive Science, 12, $257-285$.

Sweller, J., Van Merriënboer, J. J. G., \& Paas, F. G. W. C. (1998). Cognitive architecture and instructional design. Educational Psychology Review, 10(3), 251-297.

Tsai, P. S., Hwang, G. J., Tsai, C. C., Hung, C. M., \& Huang, I. (2012). An electronic library-based learning Environment for supporting web-based problem-solving activities. Educational Technology and Society, 15(4), 252-264.

Tseng, Judy C. R., Hwang, G. J., Tsai, P. S., \& Tsai, C. C. (2009). Meta-analyzer: A web-based learning environment for analyzing student information searching behaviors. International Journal of Innovative Computing, Information and Control, 5(3), 567-579.

Tzeng, J. Y. (2009). The impact of general and specific performance and self-efficacy on learning with computer-based concept mapping. Computers in Human Behavior, 25(4), 989-996.

von Glasersfeld, E. (1995). A constructivism approach to teaching. In L. P. Steff, \& J. Gale (Eds.), Constructivism in education (pp. 3-15). NJ: Lawrence Erlbaum Associates.

Vygotsky, L. S. (1986). Thought and language, A. Kozulin (Ed. and Trans.), Cambridge, MA: MIT Press.

Wang, S. L., \& Hwang, G. J. (2012). The role of collective efficacy, cognitive quality, and task cohesion in computer-supported collaborative learning. Computers and Education, 58(2), 679-687.

Wu, P. H., Hwang, G. J., Milrad, M., Ke, H. R., \& Huang, Y. M. (2012). An innovative concept map approach for improving students' learning performance with an instant feedback mechanism. British Journal of Educational Technology, 43(2), 217-232.

Zimmerman, B. J. (2000). Self-efficacy: An essential motive to learn. Contemporary Educational Psychology, 25(1), 82-91.

Dr. Hui-Chun Chu is currently an Assistant Professor in the Department of Computer Science and Information Management at Soochow University in Taiwan. Her research interests include mobile and ubiquitous learning, digital game-based learning, information technology-applied instructions and knowledge engineering.

Dr. Gwo-Jen Hwang is a Chair Professor in the Graduate Institute of Digital Learning and Education, National Taiwan University of Science and Technology, Taiwan. His research interests include mobile and ubiquitous learning, digital game-based learning, artificial intelligence in education, and web-based learning.

Yi-Rong Liang is a graduate student in the Department of Information and Learning Technology, National University of Tainan, Taiwan. His research interests include web-based learning and concept mapping. 